\title{
Diagnóstico precoce da doença de Alzheimer: contribuição da neuroimagem estrutural
}

Chetelat G., Baron JC. Early diagnosis of Alzheimer's disease: contribution of structural neuroimaging.

Neuroimage 18: 525-541, 2003

Comentado por Cássio M.C. Bottino

\section{Recebido: 26/6/2003 Aceito: 27/6/2003}

Em uma revisão recente da literatura Chetelat e Baron (2003) compararam estudos transversais (17), que avaliaram sujeitos com risco de desenvolver demência, a pacientes com doença de Alzheimer (DA) e controles idosos. Considerando os sujeitos classificados como portadores de prejuízo de memória associado à idade (PMAI), ou portadores do alelo ApoE4, os resultados foram negativos ou divergentes. Nos sujeitos com prejuízo de memória isolado (entre estes, aqueles classificados como portadores de comprometimento cognitivo leve-CCL) comparados aos controles idosos, os estudos consistentemente mostraram atrofia do hipocampo, que variou de $11 \%$ a $23 \%$. Coerentes com estudos histopatológicos, as pesquisas revisadas descreveram atrofia do córtex entorrinal nos sujeitos com CCL comparados aos controles. Os volumes do hipocampo e do córtex entorrinal mostraram capacidade semelhante para separar esses dois grupos de sujeitos (acurácia variando de 66\% a 73\%). Em geral, a diferença entre os pacientes com DA e os sujeitos com CCL parece ser menor com relação ao hipocampo e maior considerando outras estruturas do lobo temporal (acurácia variando de 70\% a 74\%). A atrofia encontrada em sujeitos com déficit de memória isolado (entre estes, aqueles com CCL) é semelhante à progressão histopatológica das lesões na DA: atrofia da região hipocampal (córtex entorrinal, hipocampo) nos pacientes com déficit de memória, e envolvimento posterior progressivo do lobo temporal (giro fusiforme, lobo temporal lateral).

Em nosso meio, foram avaliados, em estudo transversal, 39 pacientes com (DA) leve à moderada, 21 pacientes com queixa de declínio de memória, sem outras doenças psiquiátricas (CCL) e 20 idosos normais (Bottino et al., 2002). As medidas de todas as estruturas avaliadas (amígdala, hipocampo e giro para-hipocampal) separaram de forma significativa ( $\mathrm{p} \unlhd 0,005)$ os pacientes com DA, dos sujeitos com CCL e controles. As medidas volumétricas à esquerda também foram significativamente diferentes entre os indivíduos com CCL e controles $(\mathrm{p} \leq 0,05)$. Esses resultados estão de acordo com a literatura internacional revisada por Chetelat $\mathrm{e}$ Baron (2003), mas apenas estudos longitudinais poderiam avaliar se a atrofia hipocampal, em sujeitos com prejuízo isolado de memória, confere um risco aumentado para o desenvolvimento de DA no futuro.

Em sua revisão, Chetelat e Baron (2003) avaliaram 11 estudos longitudinais com RM em sujeitos com risco de desenvolver demência. Nos estudos, foram utilizados critérios diferentes para classificar os sujeitos, seguidos por dois a quatro anos, apresentando uma taxa de conversão de $0 \%$ a $69 \%$. As estruturas que melhor predisseram a conversão para demência foram: fissura peri-hipocampal, giro para-hipocampal, córtex entorrinal, hipocampo, giro fusiforme e lobo temporal lateral. Algumas limitações metodológicas devem ser consideradas, como o pequeno tamanho das amostras, heterogeneidade com relação à idade e desempenho cognitivo, aparelhagem com baixa resolução, e diferentes métodos de avaliação das estruturas cerebrais. Dois grupos de pesquisa independentes publicaram estudos recentes que não apresentavam as limitações citadas anteriormente. Em um seguimento de 2,7 anos, o hipocampo foi um preditor de conversão estatisticamente significativo (independentemente de outras variáveis, inclusive o desempenho da memória), com o grupo de

\footnotetext{
Doutor em Medicina pela FMUSP. Médico Assistente e Coordenador do PROTER - Instituto de Psiquiatria do HCFMUSP.

Endereço para correspondência:

Instituto e Departamento de Psiquiatria da FMUSP

Rua Dr. Ovídio Pires de Campos s/n, São Paulo, SP - CEP 05403-010

E-mail: cbottino@usp.br
}

Chetelat, G.; Baron, J.C.

Rev. Psiq. Clín. 30 (3):100-101, 2003 
sujeitos com CCL com o maior grau de atrofia apresentando a maior taxa de conversão para demência ( $46 \%$ versus $15 \%$ para o grupo sem atrofia). Em outra pesquisa, o volume do córtex entorrinal isolado, assim como combinado ao volume do lobo temporal superior, diferenciou-se significativamente os idosos saudáveis dos que não converteram (acurácia de $83 \%$ e $85 \%$ respectivamente) e dos que converteram para demência (acurácia de $84 \%$ e $93 \%$, respectivamente), em três anos de seguimento. Somente a combinação do lobo temporal superior e do cíngulo anterior contribuiu significativamente para discriminar entre os que converteram e os que não converteram para demência (acurácia de 75\%).

Em resumo, os estudos longitudinais revisados sugerem que o hipocampo tem um valor significativo para predizer a conversão para DA. Entretanto, esse valor é moderado, talvez porque a atrofia hipocampal esteja associada ao comprometimento de memória episódica, sendo ou não parte de uma DA incipiente. Por outro lado, uma taxa aumentada de atrofia do neocórtex temporal parece predizer a DA incipiente, e diversos estudos enfatizaram o valor preditivo de combinações como o neocórtex temporal associado ao hipocampo ou ao cíngulo anterior. Esses resultados sugerem que o diagnóstico precoce da DA, com imagem estrutural, não poderá ser feito apenas com a avaliação do lobo temporal medial (que é sensível, mas pouco específico), porém deve envolver a avaliação de outras áreas, tais como o neocórtex temporal e o cíngulo anterior, que podem mostrar atrofia menos evidente, mas conferem maior especificidade, uma vez que são afetadas apenas na DA clinicamente provável.

\section{Referências bibliográficas}

Bottino, C.M.; Castro, C.C.; Gomes, R.L.; Buchpiguel, C.A.; Marchetti, R.L.; Neto, M.R. - Volumetric MRI Measurements can Differentiate Alzheimer's Disease, Mild Cognitive Impairment, and Normal Aging. International Psychogeriatrics 14: 59-72, 2002.

Chetelat, G. \& Baron, JC. - Early Diagnosis of Alzheimer's Disease: Contribution of Structural Neuroimaging. Neuroimage 18:525-41, 2003. 